\title{
Conceptualization and Linguistic Expression: Using Religious Poetry in ELT
}

\author{
Amrita Sharma \\ Department of English \\ BPS Women's University \\ Khanpur Kalan, Sonipat \\ E-mail: spectrum_1111@yahoo.com
}

Doi:10.7575/aiac.alls.v.5n.5p.101

URL: http://dx.doi.org/10.7575/aiac.alls.v.5n.5p.101
Received: 28/06/2014

Accepted: 26/08/2014

\begin{abstract}
Religious poetry is, a heightened and impregnated form of expression. There is a marriage of form and sense. Linguistically speaking, religious poetry has a conceptual interface between syntax and semantics; a strong relationship between language and thought; universality and cultural specificity; the discourse context and the psychological environment of linguistic performance. This papers, tries to investigate how this unique genre of religious poetry be used to teach and understand the mode of conceptualization? Which language items can be taught? How does language synergize itself to open its door to create such innumerous possibilities? An attempt to answer these aforesaid questions is done by structuring this paper into three sections viz. Language and Conceptualization, The Domain of Conceptualization, Teaching English Language Items.
\end{abstract}

Keywords: Poetry, Conceptualization, Cognition, ELT

\section{Introduction}

The ability to speak, write and the ability to conceptualize are very closely linked with each other. A learner needs both these skills together at the same time. As 18th-century thinkers felt that human rationality developed and went hand in hand with the use of language; some early cognitivists like Berkeley (1710), David Hume (1738), J.S. Mill (1869) ; Locke (1690) Vico (1735), Rousseau (1750) tried to answer the question how in humans' progressive understanding and conceptualizing of the world they live in, a good deal of the flexibility of languages gets exploited with regards to conceptualization, meaning and cognition viz-a-viz linguistic expression. As Talbot (1992) puts it :

"Scholars of the eighteenth century have perhaps even a special responsibility to reconsider their assumptions about theories of language in the Enlightenment, for the eighteenth century revolutionized perspectives on the origin and nature of language. These new theories, moreover, inspired a wave of new developments in many otherwise disparate fields, from anthropology to literary criticism, from cognitive philosophy to political propaganda." (p. 266)

Different cultures and different periods have seen this process being developed in diverse ways. The anthropological linguist, Edward Sapir (1929) says that the 'real world' is to a large extent unconsciously built up on the language habits of the group. James Britton (cited in Dale Spender, 1980) states, "The objects and events of the world do not present themselves to us ready classified" rather the "categories into which they are divided are the categories into which we divide them." (p. 23)

Susanne Langer (quoted in Spender, 1980) has pointed out that human beings are symbolizing creatures (it is, perhaps, our capacity to symbolize that differentiates us from other species), and we are constantly engaged in the process of producing symbols as a means of categorizing and organizing our world. [...] It is our capacity to symbolize and the use (or misuse) we make of the symbols we construct, that constitutes the area of language, thought and reality. However, it is interesting to note that on the one hand there is considerable evidence that not all human beings are led to the same view of the world by the same physical evidence. The Sapir-Whorf hypothesis speaks of our perception of the world and reality thereof formulating that it is language, which determines the limits of our world. Language is not neutral. It is not merely a vehicle, which carries ideas. It is itself a shaper of ideas, it is the programme for mental activity The programme for encoding and decoding linguistic signs and symbols, for translating and calculating, is set up by the language, which we possess. What we see in the world around us, a large part of it depends on the principles we have encoded in our language:

“...each of us has to learn to see. The growth of every human being is a slow process of learning 'the rules of seeing', without which we could not in any ordinary sense see the world around us." (Raymonds, 1975, p. 33) 
Religious poetry pitches in, here, as an effective resource material in ELT since it corresponds not only with a reality which is immediate but also to a reality which is immanent and transcendental - it is a beautiful mode of catching the highly abstract realm of ideas; it has the competence of gathering infinite thoughts into words. To borrow words from Susan Sontag (1975) to define the linguistic character of religious poetry, she makes an interesting observation that language is a privileged metaphor for expressing the mediating character of art-making -- the artwork and silence is a metaphor for cleansed, non-interfering vision. It is here that poetry, generally speaking, scores better than other genres of literature with regard to teaching language and conceptualization.

\section{Language and Conceptualization}

Generally speaking, a concept is an idea of something formed by mentally combining

all its characteristics or particulars -- a construct ; and the ability to do it termed as conceptualization. Conceptualization springs from cognitive structures -- the term is apt because "cognitive" means "knowledge" and "structure" implies organization, and that indeed is what we possess - an organization of knowledge. Cognition then becomes a group of mental processes that are inner mental states from which understanding results. Understanding or comprehension, to borrow words from psycholinguist Frank Smith (2004), may be regarded as the relating aspect of the world around us including what we read - to the knowledge, intentions and expectation we already have in our head. Comprehension, hence means absence of confusion which comes by finding answers to the questions propped by prediction, thinking and meta-thinking skills. Therefore, the process of conceptualization involves processing information by the brain, use of perception, memory, reasoning and judgment. Nevertheless, conceptualization varies across culture, communities and even individuals.

Further, it is noteworthy that after the dawn of cognitive revolution in 1950 s, there were two distinct ideas about the nature of mind. Firstly, Noam Chomsky did establish the notion of LAD and 'autonomy of syntax' hypothesis contrasting the dominant psychological theory of Behaviourism. He argued, that, children/learners need to come to a task with rich set of expectation about the nature of language rather than general problem-solving and regularityextraction skill. Secondly, computer scientists and psychologists like Alan Newell (1956), John Anderson (1983), Patrick Henry Winston (1993) etc. began to describe a range of human abilities from visual object recognition to use of metaphor and technique of story telling/ story understanding in terms of set of internal representation and processes that transform those representations. This gave rise to AI models of language and language-cognition relationship.

In recent years, cognitive linguists and philosophers like George Lakoff and Mark Johnson (1980), Eve Sweetser (1997; 2009), cognitive rhetorician Mark Turner (2002), , Ramond Gibbs (1994), and legal theorist Steven Winter (2001), among a growing group of cognitive scientists, have provided detailed work demonstrating that grounded into human experience of each kind - cultural, perceptual, social and physical, we express the way we experience the world. The various dimensions of human experiences of the outside world are manifested in the form of objective reality and they are expressed in the form of subjective imagination of the writer.

\section{The Domain of Conceptualization}

A conceptual domain can be any coherent organization of human experience. The concepts that govern our thought are not just matters of the intellect. They also govern our everyday functioning, down to the most mundane details. It shapes how we really see the world. Besides, echoing French Linguist Gilles Fauconnier (2002), it is not out of place to say that cognition outlines within language, the structuring of basic conceptual categories such as space and time, scenes and events, entities and processes, motion and location, force and causation. It addresses the structuring of ideational and affective categories attributed to cognitive agents, such as attention and perspective, volition and intention. In doing so, it develops a rich conception of grammar that reflects fundamental cognitive abilities: the ability to form structured conceptualizations with multiple levels of organization, to conceive of a situation at varying levels of abstraction, to establish correspondences between facets of different structures, and to construe the same situation in alternate ways.

Generally speaking, when language has to be produced, conceptualization takes place as mapping between conceptual domains corresponding to neural mappings in the brain. Mapping is, actually the systematic set of correspondences that exist between constituent elements of the source domain and the target domain. Lakoff understands source as the knowledge used as resource to express the intended thoughts in conceptualization whereas the thoughts on which the knowledge is applied is called the target domain. Many elements of target concepts come from source domains and are not preexisting. Mark Schorer (cited in Selden, 2008) calls this a difference between content or experience and the achieved content as technique - a means of discovering, exploring and developing his subject and conveying his meaning.

In order to understand the domain of conceptualization properly, an example is being culled and cited from a Tamil saint-seer-poet Maharishi Ramana's poem The Marital Garland of Letters, which conceptualizes a custom in Hindu marriages for a bride to put a garland around the bridegroom's neck symbolizing the union of two persons sought in marriage physically, mentally and spiritually. Metaphorically, the experiential, material world of the source domain is mapped to the abstract wherein the soul-bride marries God, the bridegroom. The poem begins with a prayer to God Ganpati to bless him: 
Here, linguistic communication occurs as a transfer of given thoughts and feelings. These thoughts and feelings are independent of and prior to the "encoding" and "decoding" processes in communication. To place the aforesaid in other words -- the linguistic information is first conceptualized, then formulated, encoded through language code and concretized through verbalization by:

\author{
Source Domain \\ A marital garland \\ Letters (Words) \\ Exchange of Garlands \\ The Act of Marriage
}

\author{
Target Domain \\ Invocation to God \\ Flowers \\ Divine Union \\ Soul meets God
}

There is a semantic mapping from the source domain to the target domain. Osgood (1979) states, "Words, like little buckets, are assumed to pick up their loads of meaning in one person's mind, carry them across the intervening space, and dump them into the mind of another".

(p. 213) Therefore, in religious poetry, meaning is, then, the actualization of the linguistic sign which presents a dichotomy between a relational invariant - sometimes called general meaning - and a variety of hierarchized contextual variants (special meanings) including the basic variant. The variants are themselves linguistic phenomena. They include diverse literal interpretation as well as figurative transfers, both metaphorical and metonymic. They are to a certain extent codified, although not completely, since the creativity associated with clauses, sentences, utterances, discourses means the possibility of providing new contexts and thus new variants. There are both habitual associations and novel associations.

\section{Teaching English Language Items}

English Language Teaching is neither just teaching parts of speech in isolation nor teaching grammar, translation or pieces of literature to the language learner; but teaching of a language includes to develop thinking skills, cognitive capacities, and communicative proficiency. Teaching the student to be able to conceptualize, decipher meaning, create and catch the subtleties of language as well as the linguistic expression, proficiently, is an area, which is generally overlooked by the teachers and language trainers alike. There is a need to earnestly acculturate resources, which can help teachers to achieve the aforesaid aim.

Generally speaking, since religion forms an essential part of our lives, society and culture, religious poetry, hymns, psalms, songs etc. can provide a rich resource to teach a language. Religious poetry certainly impregnates universality and creativity simultaneously. We come closest to the essence of language itself in poetry; and in religious poetry, one encounters strangeness and impermeability along with its revelatory character of language as linguistic expression.

In the scope of this present paper, it is not feasible to take up all linguistic items separately. Therefore, some dominant linguistic features and items are presented below by taking recourse to a few examples from religious poetry of Maharishi Ramana:

\section{$\underline{\text { Lexis }}$}

An examination of the lexical structure of languages throws some light on the relations between various aspects of human conceptualization. Spatial relations and their expression seem to lie very deep in the content of vocabulary. Words referring to time are drawn metaphorically from spatial words with great frequency: a long/short, the near future, far ahead/separated in time, forever etc.

- Culling an example from The Collected Works of Maharishi Ramana:

Am I then worse than a dog? Steadfastly will I seek Thee and regain Thee,

Oh! Arunachala! (p. 86-87)

The above bold-marked words again represent spatial relation between God, the Master and Maharishi who sees himself metaphorically as a faithful dog. Conceptualization works through the characteristic of a dog to search his master by his smell and this is the latent yet existing elements in the source domain.

\section{- Space and time}

I am ever at Thy feet, like a frog

(which clings) to the stem of the lotus ( The Collected Works, 99)

The word "ever" presents the space and time relationship here. Besides, conceptual mapping processes itself through a simile that a frog clings to the stem of the lotus to save its body; similarly, a body-conscious person just thinks to save himself in the pool of this material world.

\section{- Binary Oppositions}

It has been maintained that the human brain has a preference for polarities. This assumption explains the numerous pairs of related antonyms that are found: good, bad; hot, cold; high, low; right, wrong; dark, light; and so on. For finer discriminations, these terms can be put into more narrowly specified fields containing more than two terms taken 
together, but their most general use is in binary contrasts. Besides, antonyms are also effective to create space and time dimensions. In religious poetry, they play an important role especially in self-inquiry and spiritual realization. For example:

Didst Thou not call me in? I have come in.

Now measure out for me, (my maintenance is now Thy burden).

Hard is Thy lot, Oh Arunachala! (The Marital Garland of Letters, 93)

- Lexical Paranomasia -- Taking again an example from The Marital Garland of Letters, referring to clothes : Tear off these robes, expose me naked, then robe me with thy love" (85)

Here, the first 'robe' refers to clothes which metaphorically stand for worldly sense entanglements and the second 'robe' refers to love which in turn metaphorically means the blessing and touch of divinity. The above example also demonstrates lexical repetition.

\section{$\underline{\text { Grammar }}$}

Grammatical items cannot only be taught but the exquisite difference of usage can also be taught using religions poetry.

\section{- Verbs referring to source.}

For example:

Thou, dost root out the ego. (82)

Mind and breath... fork out like two branches. ( The Collected Works, 111)

These verbs refer to their source thereby connecting conceptual domains.

- Denominal and Agent Verb -- Zolton (2010) has discussed work done by Clarke and Clarke on denominal verbs. In The Marital Garland of Letters, wherein the central idea of the soul-bride marrying God, the bridegroom runs throughout the poem in such beautiful expressions, the use of such verbs is found:

honour me with the union with thyself (84),

tear off these robes, expose me naked, then robe me with thy love ( 85),

Enfold me body to body, limb to limb, or I am lost ( 88) and

Espouse me, I beseech Thee ( 90 ).

The tone of the poem is evocative of earnest request interspersed with taunt in :

thou didst aim (at me) with darts of love and then devoured me alive (93)

and

Does it not shame thee to stand like a post, (leaving me) to find thee by myself? (88).

The above quoted lines from the poem, grammatically speaking, display a remarkable use of agent verbs like: bless, honour, tear off, robe, enfold, espouse, beseech, shame, find. These verbs act as the cognitive links in the conceptualization metaphorically.

- Questioning (Structure as well as the Tone) is an effective technique used in religious poetry. For example:

How then has one so weak as I offended Thee

that Thou dost leave the task unfinished?

Why dost Thou torture me thus,

keeping me suspended between life and death?

( Eleven Verses to Sri Arunachala, 99)

The metaphor represents the struggle of the devotee to realize Self. The regret is that he is still hanging between life and death. The question in the last line shows his mental agony.

- Structural and Lexical combination in Images: This technique can combine phrases, clauses, sentences as well as distinct and/or subordinate concepts. Within the range of the structural and lexical possibilities of a language, speakers are able to convey their emotional attitudes and feelings toward the person or persons they are addressing and toward the subject matter of what they are saying. They are also able to conceal such feelings as one form of linguistic deception, though this is usually a harder task. These same resources are also exploited to arouse appropriate feelings and responses in others, again independently of any factual content. This is the chosen field of the propagandist, the preacher, the orator, the barrister, and the advertiser. 
For example, in The Marital Garland of Letters, two conventionally accepted

metaphoric images in ordinary life i.e. light is life and events are actions are combined:

Dazzling Sun that swallowest up all the universe in

Thy rays, open the lotus of my Heart, I pray,

Oh Arunachala!! (85)

It is the sunlight, which gives life to mankind and plants. Lotus in a pond opens with the sun rising in the morning. Lotus is a metaphor for the heart of a devotee, which opens with the sunlight of the grace of God. These two metaphors make the idea of spiritual ripeness clear. Lotus in Hindu mythology stands for both beauty and non-attachment as it remains pious and pure even when it lives in mud and water. This is how man should live in the world - discharging duties without attachment. Maharshi combines the two metaphoric images to demonstrate the way to live in the world. It is only by the grace of God Arunachala (metaphorically Sun) which bestows light to open the lotus of heart.

\section{Conclusion}

Though the examples cited above are not exhaustive, yet they are enough to suggest that religious poetry, can certainly be used as a powerful resource in ELT to teach not only linguistic items of language but also how conceptualization is done as process and product, based on concrete experiences of routine life formulated on the abstractions of the aspects of religion metaphorically whether we talk about eternity, soul, life, death, bliss and liberation or the common material world, regular life and its realities. Religious poetry also sensitizes the learner with everyday human experiences and the abstract experiences that are made concrete through conceptualization striving to seek the most profound and ultimate truth beyond all complexities of life.

Using religious poetry in ELT not only reduces stress and anxiety which stand a barrier in learning any language but also help the learner to have pragmatic command on language and its various usage, to develop HOTS (Higher Order Thinking Skills), strong cognitive and creative abilities. To borrow words from Andrew Ortony (1993), using religious poetry in ELT provide alternative or new ways of viewing the world whereas so-called literal language has been considered too restrictive because of its inability to provide those perspectives.

\section{References}

Anderson, John (1983). The Architecture of Cognition. Cambridge, MA: Harvard University Press. Boring, E. G. (1950). A History of Experimental Psychology. New York, Appleton-Century-Crofts. Britton, James (1970). Language and Learning. London: Penguin Books.

Fauconnier, Gilles and Turner, Mark (2002). The Way We Think: Conceptual Blending and the Mind's Hidden Complexities. New York: Basic Books.

Gibbs, Raymond W. (1994). Poetics of Mind. Cambridge: Cambridge University Press.

Innes, Robert (2008). Susanne Langer in Focus: The Symbolic Mind. Bloomington, IN: Indiana University Press.

Kövecses, Zoltán (2010). Metaphor: A Practical Introduction. Oxford: Oxford University Press.

Lakoff, George and Mark Johnson (1980). Metaphors We Live By. Chicago: The University of Chicago Press.

Lucy Burke, Tony Crowley, Alan Girvin (2000) The Routledge Language and Cultural Theory Reader. (ed.) Psychology Press.

Myriam Bouveret and Eve Sweetser (2009). Multi-Frame Semantics, Metaphoric Extensions and Grammar. BLS 35.

Ortony, Andrew (1993). Metaphor and Thought. Cambridge: Cambridge University Press.

Osborne, Arthur (2000). Be Still, It Is The Wind That Sings. Tiruvannamalai: Sriramanasramam.

Osgood, Charles E. (1979). Focus on Meaning: Explorations in Semantic Space. Mouton Publishers.

Russell, Stuart J. and Peter Norvig (2003). Artificial Intelligence: A Modern Approach (2nd ed.). New Jersey: Prentice Hall.

Santog, Susan (1974). "Aesthetics of Silence" Twentieth Century Criticism: The Major Statements. ed. Willaim J. handy and Max Westbrook (pp. 453-473). New Delhi: Light and Life Publishers.

Selden, Raman, Peter Brooker and Peter Widdowson (2008) A Reader's Guide to Contemporary Literary Theory (English). $5^{\text {th }}$ ed. New Delhi: Pearson India.

Smith, Frank (2010). Understanding Reading: A Psycholinguistic Analysis of Reading and Learning to Read. U.K. Tylor and Francis.

Spender, Dale (1980). Man Made Language. (pp. 138-144). London: Pandora.

Sweetner, Eve (1997). "Role and Individual Readings of Change Predicates". In Language and Conceptualization, eds. J. Nuyts and E. Pederson. Oxford: Oxford University Press.

Talbot, J. Taylor. (1992). Mutual Misunderstanding: Scepticism and the Theorizing of Language and Interpretation. Durham \& London: Duke University Press.

Williams, Raymond (1975). The Long Revolution. London: Pengu.

Winston, Patrick Henry. (1993). Artificial Intelligence. $3^{\text {rd }}$ Ed. New York: Addison-Wesley.

Winter, Steven. (2001) A Clearing in the Forest: Law, Life and Mind Chicago: Univ. of Chicago Press. 